\title{
Impaired Bone Formation with a High-Protein Diet in Rats with Adriamycin-Induced Nephrotic Syndrome
}

\author{
A Young Lim ${ }^{\mathrm{a}}$ Su Yeon Kim ${ }^{\mathrm{a}}$ In Seok Lee ${ }^{\mathrm{a}}$ Ryowon Choue ${ }^{\mathrm{a}, \mathrm{b}}$ \\ ${ }^{a}$ Department of Medical Nutrition, Kyung Hee University, Yongin, and ${ }^{b}$ Research Institute of Medical Nutrition, \\ Kyung Hee University, Seoul, Korea
}

\section{Key Words}

Nephrotic syndrome $\cdot$ High-protein diet $\cdot$ Proteinuria $\cdot$

Bone mineral density $\cdot$ Calcium

\begin{abstract}
Background/Aim: The purpose of the study was to investigate the effects of a high-protein (HP) diet on bone metabolism in rats with adriamycin (ADR)-induced nephrotic syndrome. Methods: Nephrotic syndrome was established by weekly injections of ADR ( $2 \mathrm{mg} / \mathrm{kg}$, i.p.) for 6 weeks. After a final injection, we confirmed that nephrotic syndrome had developed. Then, the rats were divided into two groups for the dietary treatments, namely the HP diet $30 \%$ of calories from protein) and the low-protein (LP) diet (7\% of calories from protein), and were fed an isocaloric diet for the following 5 weeks. Results: Urinary protein and phosphate excretion were significantly greater in the HP diet group than in the LP diet group $(p<0.05)$. Serum parathyroid hormone and osteocalcin levels were significantly higher and lower, respectively, in the HP diet group $(\mathrm{p}<0.05)$. Femur weight, femur mass index and femur calcium contents were significantly lower in the HP diet group than in the LP diet group $(p<0.05)$. Bone mineral density was significantly lower in the HP diet group than in the LP diet group $(p<0.05)$; however, bone mineral content did not differ between the two groups.
\end{abstract}

Conclusion: We confirmed that an HP diet negatively affects bone mineral metabolism and bone density in ADR-induced nephrotic syndrome rats.

Copyright $\odot 2012$ S. Karger AG, Basel

\section{Introduction}

Nephrotic syndrome is a renal dysfunctional state that can be caused by disorders of capillary vessels contained in the kidney nephrons [1]. Since Denis and Hobson [2] initially reported that a high level of calcium excretion and reduced calcium absorption with excessive urinary protein excretion are accompanied by hyperproteinuria in nephrotic syndrome and lead to hypocalcemia, many studies have been performed to investigate the mechanisms of impaired bone metabolism in nephrotic syndrome.

Generally, there are several factors that lead to hypocalcemia in nephrotic syndrome. Firstly, the secretion of 1-dehydroxylase in the kidney is decreased, which results in low levels of $1,25-(\mathrm{OH})_{2} \mathrm{D}_{3}$, which in turn promotes absorption of calcium from the intestine [3]. Secondly, proteinuria increases the loss of vitamin $\mathrm{D}$-binding protein, which carries vitamin $\mathrm{D}$ and the precursor of $25(\mathrm{OH})$ $\mathrm{D}_{3}[1,4,5]$. Lastly, calcium reabsorption decreases in re- 
nal tubules as the glomerular filtration rate increases [6]. Hypocalcemia accelerates the secretion of parathyroid hormone (PTH) from the parathyroid glands, which causes hyperparathyroidism and increases the calcium resorption from bone to serum [5]. Hypocalcemia, induced by excessive urinary protein excretion and hyperparathyroidism, affects bone metabolism in nephrotic syndrome [5, 7]. In particular, it has significant effects on bone mineral density in growing children with nephrotic syndrome [8].

To date, many studies have reported that excessive dietary protein induces negative effects on bone metabolism, although these data are limited for nephrotic syndrome [9]. In fact, according to many studies, a high-protein (HP) diet builds up a large quantity of urea, increases urine volume, leads to renal hypertrophy and causes excretion of large amounts of minerals, including calcium, and vitamin $\mathrm{D}$ metabolites from the body [10, 11]. Excessive dietary animal protein in particular enhances calcium resorption from bones to neutralize sulfur-containing amino acids [12].

Although an HP diet accelerates proteinuria, which can cause a variety of symptoms of nephrotic syndrome, such as hypocalcemia, hyperparathyroidism and abnormal bone formation, dietary guidelines for nephrotic syndrome patients have not been established. We designed the present study to demonstrate the importance of dietary protein proportion on bone metabolism in nephrotic syndrome.

The purpose of this study was to investigate the effects of an HP diet on bone metabolism in rats with nephrotic syndrome induced by the injection of adriamycin (ADR), which degenerates renal function [13].

\section{Materials and Methods}

\section{Animals and Diets}

The experimental protocol was approved by the Animal Care and Use Review Committee of Kyung Hee University. A total of 24 4-week-old male Sprague-Dawley rats (150-170 g) were purchased from SLC Inc. (Shizuoka, Japan). Rats were housed in polycarbonate cages in temperature-controlled rooms $\left(22 \pm 2{ }^{\circ} \mathrm{C}\right)$, with a relative humidity of $55 \pm 5 \%$ and a 12 -hour light/dark cycle. The rats were fed a pellet chow diet and were given water ad libitum for an adaptation period of 2 weeks.

After 2 weeks of adaptation in a metabolic cage, the animals $(\mathrm{n}=24)$ received weekly $1.0-\mathrm{ml}$ intraperitoneal injections of $2 \mathrm{mg} /$ kg body weight ADR (doxorubicin, D1515, Sigma, St. Louis, Mo., USA) and were given water and AIN93G pellets (Research Diets, USA) ad libitum for 6 weeks to induce ADR-induced proteinuria, which has been well characterized as an experimental model for nephrotic syndrome. After nephrotic syndrome was confirmed from urinary and blood data $(\mathrm{n}=8)$, ADR-treated animals $(\mathrm{n}=$ 16) were placed into one of two different groups, an HP diet group ( $\mathrm{n}=8 ; 30 \%$ of calories from protein and $7 \%$ from fat) or a lowprotein (LP) diet group ( $\mathrm{n}=8 ; 7 \%$ of calories derived from protein and $40 \%$ from fat) for the remaining 5 weeks. Both diets contained equal numbers of calories to prevent effects due to differences in calorie intake.

\section{Body Weight and Food Consumption}

Body weight and food consumption were measured weekly. The food efficiency ratio was calculated using the following formula: [weight gain (g)/day]/[amount of food consumed (g)/day].

\section{Urine Sample Analysis}

For 24-hour urine collection at 0,3 and 5 weeks, the animals were housed in metabolic cages. During the urinary collection period, rats were restrained from eating to avoid contamination of the urine; however, they were allowed free access to water. Instruments used for collecting urine were washed with $0.1 \mathrm{~N} \mathrm{HCl}$ to prevent rot of the urine. Urine samples were centrifuged at 2,000 rpm for $15 \mathrm{~min}$ at room temperature, and the top layer was collected and stored at $-70^{\circ} \mathrm{C}$ until analysis. The Bradford method was applied to determine urinary protein levels. Urinary calcium and inorganic phosphorus in the urine were determined by a chemistry autoanalyzer (Advia 1650, Bayer, Japan).

\section{Blood Sample Analysis}

Blood was collected at 0 and 5 weeks, following a 12-hour overnight fast. Rats were lightly anesthetized with ethyl ether, and blood samples were taken by heart puncture. Blood samples were immediately collected into EDTA-containing tubes and serumseparating tubes to separate the plasma and serum, respectively. Blood was centrifuged at $3,000 \mathrm{rpm}$ for $15 \mathrm{~min}$ at $4^{\circ} \mathrm{C}$, and the top layer (serum) was stored at $-70^{\circ} \mathrm{C}$ until use in assays.

Serum ionized calcium was measured using an EML 100 (Radiometer, Copenhagen, Denmark), and serum calcium and inorganic phosphorus were determined by a chemistry autoanalyzer (Advia 1650, Bayer). Serum PTH, osteocalcin and osteopontin were measured in duplicate using Millipore's MILLIPLEX Bone Hormone Panel (Millipore, Billerica, Mass., USA). The plate was run on a Luminex 200 instrument using Bio-Plex Manager 4.1 standard software (Bio-Rad Laboratories, Hercules, Calif., USA). Alkaline phosphatase (ALP) was determined using commercial kits (Alkaline Phosphate Reagents, Bayer, Tarrytown, N.Y., USA) with an Advia 1650 (Bayer). Serum 1,25- $(\mathrm{OH})_{2} \mathrm{D}_{3}$ was determined using commercial kits (1,25-Dihydroxy Vitamin D ${ }^{125}$ I RIA kit, DiaSorin, Stillwater, Minn., USA) with a gamma counter (Cobra 5010 Series Quantum, Packard, Meriden, Conn., USA).

\section{Analysis of Femur Samples}

Bone samples were obtained after rats were sacrificed at 0 and 5 weeks. The right femur was collected and freed from soft tissue. The femurs were stored in $4 \%$ formalin. The ash content in the femur was measured by heating at $500^{\circ} \mathrm{C}$ for $2 \mathrm{~h}$ in an electric furnace, and then $10 \mathrm{ml}$ of $6 \mathrm{~N} \mathrm{HCl}$ solution was added and diluted to the adequate concentration for analysis of calcium. Calcium content in the femur was determined by atomic absorption spectrophotometry at $422.7 \mathrm{~nm}$. Bone mineral density and bone mineral content were measured by dual-energy X-ray absorptiometry measurements (PlXlmus 2, GE Lunar Co., Madison, Mich., USA). 


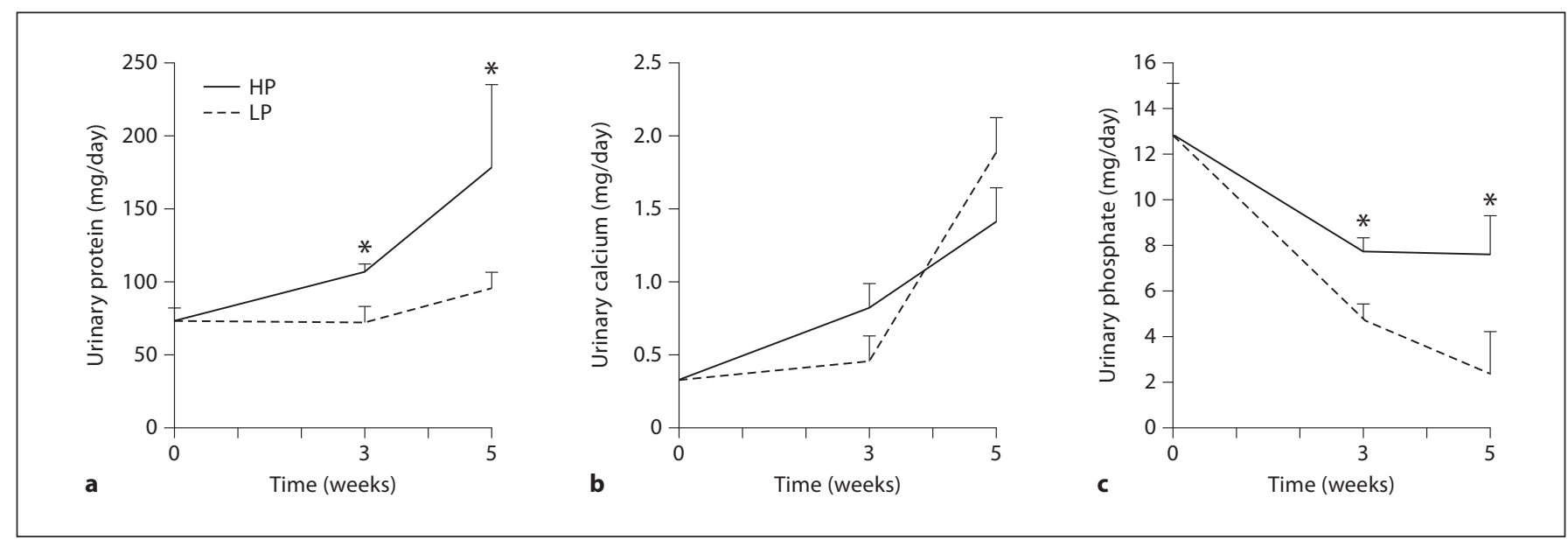

Fig. 1. Urinary excretion of protein $(\mathbf{a}), \mathrm{Ca}(\mathbf{b})$ and $\mathrm{P}(\mathbf{c})$ in the $\mathrm{HP}$ and LP groups. ${ }^{*} \mathrm{p}<0.05$ : statistical difference between the two groups (Student's t test).

Statistical Analysis

All measurements were performed in duplicate, and statistical calculations were performed with SPSS statistical software for Windows, version 13.0. All data are presented as means \pm SD. Differences in measured parameters between the experimental groups were analyzed by Student's t test. The differences were considered to be significant when the p value was less than 0.05 .

\section{Results}

Body Weight, Kidney Weight, Intake of Calories, Ca and $P$, and Food Efficiency Ratio

The mean values of body weight, kidney weight, intake of calories, $\mathrm{Ca}$ and $\mathrm{P}, \mathrm{Ca} / \mathrm{P}$ ratio and the food efficiency ratio are shown in table 1 . Body weights of the rats in the HP and LP diet groups were not significantly different, neither at the beginning nor at the end of the experiment. Kidney weight was greater in the HP group (3.39 \pm $0.58 \mathrm{~g})$ than in the LP group $(2.42 \pm 0.15 \mathrm{~g})$ at the end of the experiment. The daily calorie intakes and food efficiency ratios of the two groups did not differ due to the isocaloric intake. Intakes of $\mathrm{Ca}$ and $\mathrm{P}$ were higher in the HP group $(72.1 \pm 1.8$ and $57.1 \pm 1.4 \mathrm{mg} /$ day, respectively) than in the LP group $(61.3 \pm 1.3$ and $26.3 \pm 0.54 \mathrm{mg} /$ day, respectively); consequently, the $\mathrm{Ca} / \mathrm{P}$ ratio was lower in the HP group (1.26:1) than in the LP group (2.33:1).

\section{Urinary Protein, Calcium and Phosphate Excretion}

Figure 1 shows the urinary excretion of protein, $\mathrm{Ca}$ and $\mathrm{P}$ in the HP and LP groups. At 5 weeks, the urinary protein excretion had increased in both groups (by 245.4
Table 1. Body weight, calorie intake, mineral intake, food efficiency ratio and kidney weight of the experimental groups

\begin{tabular}{lll}
\hline & HP & LP \\
\hline Initial body weight, g & $366.4 \pm 16.4$ & $374.3 \pm 11.4$ \\
Final body weight, g & $411.5 \pm 12.1$ & $415.5 \pm 13.0$ \\
Weight gain, g & $40.0 \pm 8.5$ & $41.2 \pm 10.3$ \\
Kidney weight, g & $0.85 \pm 0.12$ & $0.66 \pm 0.04^{*}$ \\
Calorie intake, kcal/day & $58.0 \pm 0.3$ & $58.4 \pm 0.5$ \\
Calcium intake, mg/day & $72.1 \pm 1.8$ & $61.3 \pm 1.3^{*}$ \\
Phosphate intake, mg/day & $57.1 \pm 1.4$ & $26.3 \pm 0.5^{*}$ \\
Calcium to phosphate ratio & $1.26: 1$ & $2.33: 1^{*}$ \\
Food efficiency ratio & $0.51 \pm 0.12$ & $0.43 \pm 0.12$ \\
\hline
\end{tabular}

Kidney weight was measured as the total weight of the right kidney plus the left kidney. The food efficiency ratio was calculated as follows: [weight gain (g)]/[food consumed (g)/day]. ${ }^{*} \mathrm{p}<$ 0.05: statistical difference between the experimental groups (Student's t test).

and $131.8 \%$ in the HP and LP groups, respectively) compared with the initial levels $(\mathrm{p}<0.05)$. There was a significant difference between the two groups at 3 and 5 weeks, with urinary excretion of protein in the HP group being significantly higher than that of the LP group (3 weeks: HP, $107.0 \pm 5.8 \mathrm{mg} /$ day, and LP, $71.6 \pm 13.1 \mathrm{mg} /$ day; 5 weeks: HP, $178.6 \pm 55.9 \mathrm{mg} /$ day, and LP, $95.9 \pm$ $8.6 \mathrm{mg} /$ day; $\mathrm{p}<0.05)$.

The urinary $\mathrm{Ca}$ excretion had increased significantly in both groups when it was compared with the initial val- 


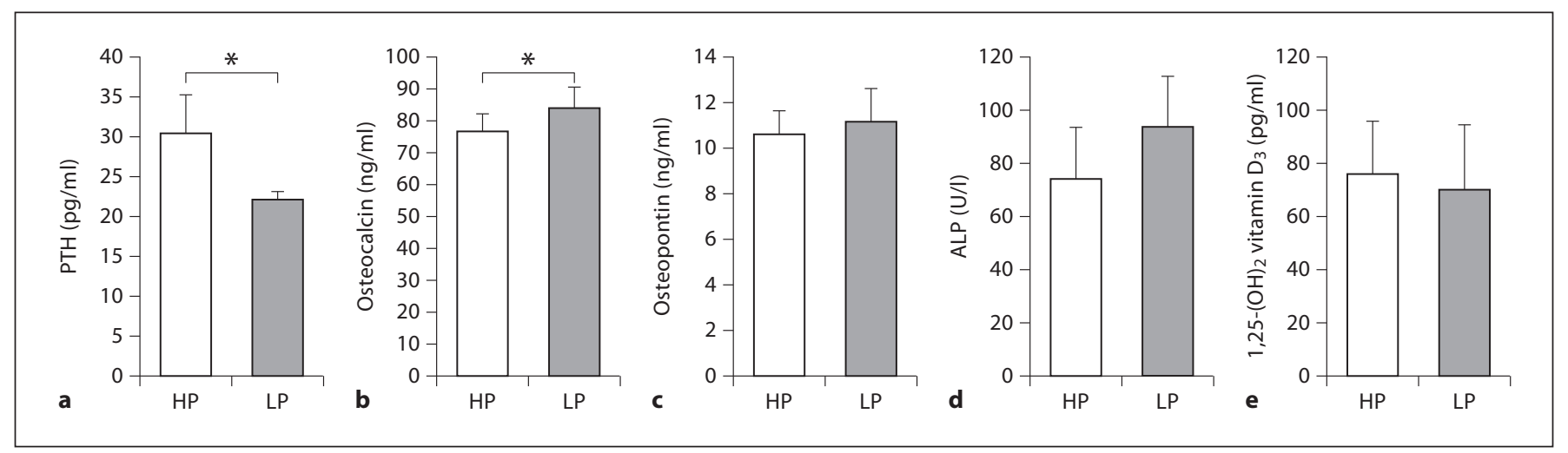

Fig. 2. Serum levels of PTH (a), osteocalcin (b), osteopontin (c), ALP (d) and 1,25-(OH) $)_{2} \operatorname{vitamin~} \mathrm{D}_{3}(\mathbf{e}) .{ }^{*} \mathrm{p}<$ 0.05 (Student's t test).

Table 2. Serum levels of calcium and phosphate in the experimental groups

\begin{tabular}{lcc}
\hline & HP & LP \\
\hline Serum Ca, mg/dl & $9.4 \pm 1.0$ & $8.6 \pm 0.5$ \\
Serum P, mg/dl & $5.3 \pm 0.8$ & $6.0 \pm 1.2$ \\
Ionized Ca, mM & $1.20 \pm 0.06$ & $1.12 \pm 0.06$ \\
\hline
\end{tabular}

Table 3. Femur wet weight, femur mass index and femur calcium content in the experimental groups

\begin{tabular}{lll}
\hline & HP & LP \\
\hline Femur wet weight, $g$ & $0.703 \pm 0.026$ & $0.777 \pm 0.028^{*}$ \\
Femur mass index & $0.171 \pm 0.006$ & $0.185 \pm 0.005^{*}$ \\
g/g body weight & $75.1 \pm 2.3$ & $80.3 \pm 5.1^{*}$ \\
\hline Femur Ca content, mg & & \\
\hline
\end{tabular}

* $\mathrm{p}<0.05$ : statistical difference between the experimental groups (Student's t test).

ues $(\mathrm{p}<0.05)$. However, there was no significant difference between the two groups at 3 and 5 weeks ( 3 weeks: $\mathrm{HP}, 0.82 \pm 0.16 \mathrm{mg} / \mathrm{day}$, and LP, $0.45 \pm 0.17 \mathrm{mg} /$ day; 5 weeks: HP, $1.41 \pm 0.23 \mathrm{mg} /$ day, and LP, $1.89 \pm 0.23 \mathrm{mg} /$ day). In contrast, the excretion of urinary $\mathrm{P}$ in both groups decreased significantly throughout the experimental period $(\mathrm{p}<0.05)$. There were significant differences in $\mathrm{P}$ excretion between the two groups at 3 and 5 weeks ( 3 weeks: HP, $7.73 \pm 1.26 \mathrm{mg} /$ day, and LP, $4.77 \pm 1.15 \mathrm{mg} /$ day; 5 weeks: HP, $7.62 \pm 0.33 \mathrm{mg} /$ day, and LP, $2.36 \pm 3.19$ $\mathrm{mg} /$ day; $\mathrm{p}<0.05$ ).

Impaired Bone Formation with a HP Diet in Nephrotic Syndrome Rats

\section{Serum Levels of Calcium and Phosphate}

Serum levels of $\mathrm{Ca}, \mathrm{P}$ and ionized $\mathrm{Ca}$ are shown in table 2. Serum Ca levels did not differ between the two groups (HP: $9.4 \pm 1.0 \mathrm{mg} / \mathrm{dl}$; LP: $8.6 \pm 0.5 \mathrm{mg} / \mathrm{dl}$ ). Similarly, there was no significant difference in the serum $\mathrm{P}$ levels between the groups (HP: $5.3 \pm 0.8 \mathrm{mg} / \mathrm{dl}$; LP: 6.0 $\pm 1.2 \mathrm{mg} / \mathrm{dl}$ ). Additionally, the ionized Ca level in the HP group $(1.20 \pm 0.06 \mathrm{mM})$ did not differ from that in the LP group $(1.12 \pm 0.06 \mathrm{mM})$.

\section{Serum Levels of PTH, Osteocalcin, Osteopontin, ALP} and 1,25- $(\mathrm{OH})_{2}$ Vitamin $\mathrm{D}_{3}$

Serum levels of PTH, osteocalcin, osteopontin, ALP and $1,25-(\mathrm{OH})_{2}$ vitamin $\mathrm{D}_{3}$ are shown in figure 2 . The mean serum level of PTH in the HP group $(30.3 \pm 5.9$ $\mathrm{pg} / \mathrm{ml}$ ) was significantly higher than that in the LP group $(22.1 \pm 1.1 \mathrm{pg} / \mathrm{ml} ; \mathrm{p}<0.05)$. In contrast, the osteocalcin levels were significantly lower in the HP group (76.8 \pm $5.2 \mathrm{ng} / \mathrm{ml})$ than those in the LP group $(83.6 \pm 6.8 \mathrm{ng} / \mathrm{ml}$; $\mathrm{p}<0.05)$. No significant differences were shown in the serum levels of osteopontin, ALP and 1,25- $(\mathrm{OH})_{2}$ vitamin $\mathrm{D}_{3}$ between the two groups.

\section{Femur Wet Weight, Femur Mass Index and Calcium Content}

Femur wet weight, femur mass index and Ca contents are shown in table 3 . The weight of the femurs and femur mass index were significantly lower in the HP group $(0.703 \pm 0.026 \mathrm{~g}$ and $0.171 \pm 0.006 \mathrm{~g} / \mathrm{g}$ body weight, respectively) than those in the LP group $(0.777 \pm 0.028 \mathrm{~g}$ and $0.185 \pm 0.005 \mathrm{~g} / \mathrm{g}$ body weight, respectively; $\mathrm{p}<$ 0.05). In addition, femur Ca content was also significantly lower in the HP group $(75.1 \pm 2.3 \mathrm{~g})$ than that in the LP group $(80.3 \pm 5.1 \mathrm{~g} ; \mathrm{p}<0.05)$. 
Fig. 3. Bone mineral density (BMD; a) and bone mineral content (BMC; b) in the whole femur and at midshaft (middle of the femur; measured area $3 \mathrm{~cm}^{2}$ ). ${ }^{*} \mathrm{p}<0.05$ (Student's t test).
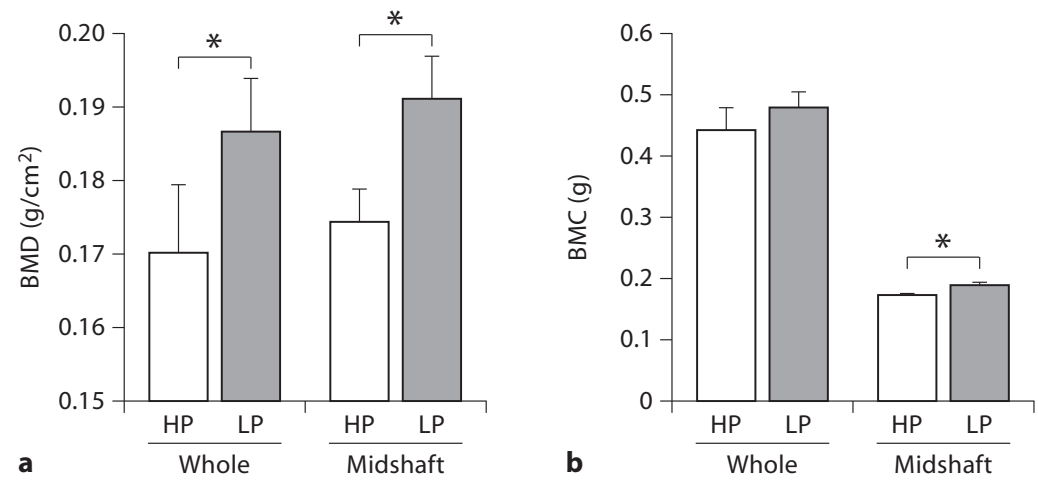

Femur Mineral Density and Femur Mineral Content in the Whole Femur and at Midshaft

The bone mineral density and bone mineral content in the whole femur and at midshaft are shown in figure 3. Bone mineral density in the whole femur and at midshaft was significantly lower in the HP group $(0.1724 \pm 0.0080$ and $0.1743 \pm 0.0045 \mathrm{~g} / \mathrm{cm}^{2}$, respectively) than that in the LP group $\left(0.1864 \pm 0.0073\right.$ and $0.1909 \pm 0.0058 \mathrm{~g} / \mathrm{cm}^{2}$, respectively; $\mathrm{p}<0.05)$. Bone mineral content in the whole femur in both groups did not differ $(0.452 \pm 0.033$ and $0.481 \pm 0.025 \mathrm{~g}$, respectively); however, bone mineral content at the midshaft of the femur was significantly lower in the HP group $(0.0318 \pm 0.0018 \mathrm{~g})$ than in the LP group $(0.0360 \pm 0.0017 \mathrm{~g} ; \mathrm{p}<0.05)$.

\section{Discussion}

This study investigated the effects of an HP diet on bone formation in ADR-induced nephrotic syndrome rats. Nephrotic syndrome has many kinds of initial symptoms such as proteinuria, hypoalbuminemia and hypercholesterolemia [14]. If those symptoms last a long period of time, some cases can progress to chronic renal failure [15], which is generally known to develop the complications of bone disorders [16]. Previous studies have reported that abnormal bone remodeling and calcium metabolism occur in nephrotic syndrome patients $[4,5,7]$, and these might be accelerated by an HP diet $[9,11,12]$.

To demonstrate the importance of dietary protein for bone metabolism in nephrotic syndrome, the nephrotic syndrome was established in rats by the intraperitoneal administration of ADR, which inhibits DNA synthesis in not only cancer cells but also normal liver and kidney cells $[13,17]$. After weekly injection of ADR for 6 weeks, we confirmed that nephrotic syndrome had developed by histology of the glomerulus (data has not shown). Thereafter, an HP (30\% of the total calories) or LP ( $7 \%$ of the total calories) diet was given to the rats.

In this study, although the body weights of both groups were not different, the kidney weights in rats fed the HP diet were significantly greater than those in rats fed the LP diet. It is generally known that kidney hypertrophy is the early step in the process of nephron damage [18].

Proteinuria is a major index for the diagnosis of renal disease. In accordance with previous studies, this study also showed that urinary protein excretion increased as time passed in both groups, and its levels in the HP diet group were significantly higher than those in the LP diet group, showing the negative effects of an HP diet on renal function. As previously demonstrated in many studies, an excess consumption of dietary protein can increase glomerular pressure and filtration, which can cause deterioration of renal function $[10,19]$.

An HP diet has been shown to be related to the abnormal metabolism of calcium and phosphate in kidney disease patients [20,21]. Human bodies preferentially maintain the homeostasis of the serum calcium concentrations; however, if the balance is skewed, hormones act to exchange calcium between blood and bone and control urinary calcium excretion. Thus, if the serum calcium level is low, then this mechanism negatively affects bone formation and remodeling [22]. In this study, the serum and urine levels of these minerals and several hormones that are related to bone metabolism were studied.

The serum levels of calcium and phosphate as well as urinary calcium excretion were not affected by the dietary protein in this study; however, urinary phosphate 
excretion increased significantly in the HP diet group. Since an HP diet accelerates kidney hyperfiltration, generally serum calcium decreases and urinary calcium increases in nephrotic syndrome patients [23]. However, some studies failed to show any changes in serum calcium or phosphate levels $[24,25]$. The homeostasis of serum minerals is maintained by a variety of hormones, such as PTH, and in the early stage of nephrotic syndrome, hormones may work to maintain the mineral balance in the serum [26].

In the case of hypocalcemia, PTH transfers calcium and phosphate from the bone to the blood and enforces calcium reabsorption as well as phosphate excretion from the kidney to maintain normal serum concentrations [27]. In the present study, the serum PTH levels were increased by the HP diet, and several previous studies showed the same results $[11,22]$. It can be speculated that to maintain the homeostasis of calcium, calcium is released from the bone, constantly accompanied by high levels of serum PTH resulting from the HP diet-induced hyperfiltration of calcium. Moreover, it can be explained that the high level of serum PTH with the HP diet made no difference in the urinary calcium excretion compared to the LP diet because the higher serum PTH caused more reabsorption of calcium from the kidney, although the urinary protein excretion was significantly higher with the HP diet. We considered that the higher serum PTH level with the HP diet led to increased urinary phosphate excretion.

In bone mineral balance, osteocalcin, a noncollagenous protein secreted solely by osteoblasts, tends to increase when bone is formed [28]. Our results showed that the serum osteocalcin level was lowered by the HP diet, showing that an HP diet negatively affected or slowed down bone formation as compared to an LP diet. A number of studies have reported similar results [29]; however, some studies showed opposite results [30]. We suggest that this discrepancy could be a result of differences in kidney clearance or filtration ability among subjects [31].

The other hormone that influences bone metabolism is 1,25 -dihydroxycholecalciferol $\left[1,25-(\mathrm{OH})_{2} \mathrm{D}_{3}\right]$. It enhances the absorption of calcium and phosphate from the gastrointestinal tract. Its serum level decreases with severe proteinuria and progressive kidney damage. When the serum calcium level is low, PTH enhances the conversion of $25(\mathrm{OH}) \mathrm{D}$ to $1,25-(\mathrm{OH})_{2} \mathrm{D}_{3}$ in the kidney [32]. Decreased vitamin $\mathrm{D}$ levels induce secondary hyperparathyroidism and increase turnover of bone [5]. Several studies have reported that plasma vitamin D metabolite levels, including $1,25-(\mathrm{OH})_{2} \mathrm{D}_{3}$, decrease in nephrotic syndrome due to the excess loss of protein through urine $[11,22,24]$. However, a few studies did not show significant differences in those levels [33]. Our results showed that serum $1,25-(\mathrm{OH})_{2} \mathrm{D}_{3}$ levels were not affected by dietary protein, even though urinary protein excretion increased exponentially with the HP diet.

ALP is an enzyme found in all tissues, and in particularly high concentrations in the bone, and is secreted more when osteoblasts accumulate in the bone matrix [34]. In the present study, the serum ALP levels were not affected by the HP diet. In a previous study, the serum levels of ALP were lower in nephrotic syndrome rats fed an HP diet [11]. In contrast, a number of other previous studies have not shown any significant differences [35].

The effects of the HP diet on bone metabolism were evaluated by measuring femur weight, calcium content, mineral density and mineral content. Almost all of these measures were significantly lower in the rats on the HP diet than in those on the LP diet. This was likely due to the increased serum levels of PTH and urinary protein excretion with the HP diet. These findings indicate that an HP diet has deteriorative effects on bone metabolism. Other researchers have also reported that an HP diet caused bone loss resulting from excessive amounts of calcium and vitamin D metabolites in urine $[9,11,36]$.

In this study, the amount of dietary calcium and phosphate and the ratio of calcium to phosphate were higher and lower, respectively, with the HP diet than with the LP diet. This could lead to increased calcium excretion with the HP diet [37]. In particular, excessive intake of phosphate from an HP diet accelerates kidney dysfunctions, such as dysregulation of the calcium and phosphate balance, and limits the conversion of $25(\mathrm{OH}) \mathrm{D}$ into $1,25-(\mathrm{OH})_{2} \mathrm{D}_{3}[38,39]$. In this experiment, the histology of the glomerulus in rats on the HP diet showed that the boundary of the glomerulus was weaker and renal tubules had bigger holes than in rats on the LP diet (data not shown). Therefore, an HP diet in nephrotic syndrome rats influenced kidney histology, resulting in abnormal bone metabolism.

In conclusion, an HP diet induced an increase in urinary protein and phosphate as well as serum PTH levels in nephrotic syndrome rats. These changes may cause the changes in the serum calcium concentration and vitamin D metabolites and, finally, decreases in femur weight, calcium content and bone mineral density of the femur. Thus, we could conclude that an HP diet might negatively affect kidney function and bone formation in ADRinduced nephrotic syndrome rats. 


\section{References}

$>1$ De Seigneux S, Martin PY: Management of patients with nephrotic syndrome. Swiss Med Wkly 2009;139:416-422.

$>2$ Denis W, Hobson S: A study of the inorganic constituents of the blood serum in nephritis. J Biol Chem 1923;55:183-190.

$\checkmark 3$ Goldstein DA, Haldimann B, Sherman D, Norman AW, Massry SG: Vitamin D metabolites and calcium metabolism in patients with nephrotic syndrome and normal renal function. J Clin Endocrinol Metab 1981;52: $116-121$.

$\checkmark 4$ Tessitore N, Bonucci E, D’Angelo A, Lund B, Corgnati A, Lund B, Valvo E, Lupo A, Loschiavo C, Fabris A, Maschio G: Bone histology and calcium metabolism in patients with nephrotic syndrome and normal or reduced renal function. Nephron 1984;37:153-159.

5 Elder GJ: Nephrotic syndrome: don't forget the bones! Nephrology (Carlton) 2008;13: 43-44.

6 Houillier P, Froissart M, Maruani G, Blanchard A: What serum calcium can tell us and what it can't. Nephrol Dial Transplant 2006;21:29-32.

7 Sierra RI, Specker BL, Jiménez F, Cruz C, Pedraza-Chaverrí J: Biochemical bone markers, bone mineral content, and bone mineral density in rats with experimental nephrotic syndrome. Ren Fail 1997;19:409-424.

$>8$ Gulati S, Sharma RK, Gulati K, Singh U, Srivastava A: Longitudinal follow-up of bone mineral density in children with nephrotic syndrome and the role of calcium and vitamin D supplements. Nephrol Dial Transplant 2005;20:1598-1603.

$\checkmark$ Wachman A, Bernstein DS: Diet and osteoporosis. Lancet 1968;i:958-959.

$\checkmark 10$ Metges CC, Barth CA: Metabolic consequences of a high dietary-protein intake in adulthood: assessment of the available evidence. J Nutr 2000;130:886-889.

11 Hammond KA, Janes DN: The effects of increased protein intake on kidney size and function. J Exp Biol 1998;201:2081-2090.

12 Barzel US, Massey LK: Excess dietary protein can adversely affect bone. J Nutr 1998; 128:1051-1053.

13 Tanaka M, Yoshida S: Mechanism of the inhibition of calf thymus DNA polymerases alpha and beta by daunomycin and adriamycin. J Biochem 1980;87:911-918.

14 Bertani T, Poggi A, Pozzoni R, Delaini F, Sacchi G, Thoua Y, Mecca G, Remuzzi G, Donati MB: Adriamycin-induced nephrotic syndrome in rats: sequence of pathologic events. Lab Invest 1982;46:16-23.
15 Tessitore N, Bonucci E, D’Angelo A, Lund B, Corgnati A, Lund B, Valvo E, Lupo A, Loschiavo C, Fabris A, et al: Bone histology and calcium metabolism in patients with nephrotic syndrome and normal or reduced renal function. Nephron 1984;37:153-159.

16 Argilés A, Vanholder R: Chronic kidney disease-related mineral and bone disorders, Nephron Clin Pract 2009;112:128-136.

17 Yilmaz S, Atessahin A, Sahna E, Karahan I, Ozer S: Protective effect of lycopene on adriamycin-induced cardiotoxicity and nephrotoxicity. Toxicology 2006;218:164-171.

18 Van Neck JW, Cingel V, Van Vliet AK, Drop SL, Flyvbjerg A: High-protein induced renal enlargement is growth hormone independent. Kidney Int 2002;62:1187-1195.

19 Brenner BM, Meyer TW, Hostetter TH: Dietary protein intake and the progressive nature of kidney disease: the role of hemodynamically mediated glomerular injury in the pathogenesis of progressive glomerular sclerosis in aging, renal ablation, and intrinsic renal disease. N Engl J Med 1982;307:652659.

20 Schaffer SW, Lombardini JB, Azuma J: Interaction between the actions of taurine and angiotensin II. Amino Acids 2000;18:305-318.

21 King AJ, Levey AS: Dietary protein and renal function. J Am Soc Nephrol 1993;3:17231737.

22 Healney RP, Weaver CM, Fitzsimmons ML: The influence of calcium load on absorption fraction. J Bone Miner Res 1990;11:11351143.

-23 Mizokuchi M, Kubota M, Tomino Y, Koide $\mathrm{H}$ : Possible mechanism of impaired calcium and vitamin $\mathrm{D}$ metabolism in nephrotic rats. Kidney Int 1992;42:335-340.

24 Chan YL, Mason RS, Parmentier M, Savdie E, Lissner D, Posen S: Vitamin D metabolism in nephrotic rats. Kidney Int 1983;24:336341.

25 Ritsuko M, Yumi N, Shinichi K, Yasutaka K, Mariko U, Shinya T, Akinori S, Shigeaki K, Toshitaka N, Kazuharu S: Dietary calcium and phosphorus ratio regulates bone mineralization and turnover in vitamin $D$ receptor knockout mice by affecting intestinal calcium and phosphorus absorption. J Bone Miner Res 2003; 18:1217-1226.

-26 Talmage RV, Lester GE, Hirsch PF: Parathyroid hormone and plasma calcium control: an editorial. J Musculoskelet Neuronal Interact 2000;1:121-126.

27 Price PA, Pathermore JG, Doftos LJ: New biochemical marker for bone metabolism. J Clin Invest 1980;66:878-883.

-28 Delmas PD: Biochemical markers of bone turnover for the clinical investigation of osteoporosis. Osteoporos Int 1993;3:81-86.
29 Ria R, Scarponi AM, Falzetti F, Ballanti S, Di Ianni M, Sportoletti P, Cimminiello M, Gasbarrino C, Pallone B, Vacca A, Dammacco F, Mannarino E, Tabilio A: Loss of bone mineral density and secondary hyperparathyroidism are complications of autologous stem cell transplantation. Leuk Lymphoma 2007;48:923-930.

30 Malluche HH, Fanti P, Faugere MC, Price PA: Plasma levels of bone Gla-protein reflect bone formation in patients on chronic maintenance dialysis. Kidney Int 1984;26:869874.

31 Delmas PD, Wilson DM, Mann KG, Riggs BL: Effect of renal function on plasma levels of bone Gla-protein. J Clin Endocrinol Metab 1983;57:1028-1030.

32 Van Hoof HJ, De Sévaux RG, Van Baelen H, Swinkels LM, Klipping C, Ross HA, Sweep CG: Relationship between free and total 1,25-dihydroxyvitamin D in conditions of modified binding. Eur J Endocrinol 2001; 144:391-396.

33 Sanjeev K, Suresh C, Suresh C, Sanjay K, Sanjeev S, Steven F: Bone histology in patients with nephrotic syndrome and normal renal function. Kidney Int 1999;55:1912-1919.

34 Aloia JF, Cohr SH, Vaswani A, Yeh JK, Yuen $\mathrm{K}$, Ellis K: Risk factors for postmenopausal osteoporosis. Am J Med 1985;78:95-100.

-35 Raguenez-Viotte G, Lahoue M, Ducastelle T, Morin JP, Fillastre JP: CCNU-adriamycin association induces earlier and more severe nephropathy in rats. Arch Toxicol 1988;61: 282-291.

36 Ekholm R, Adami J, Tidermark J, Hansson K, Törnkvist H, Ponzer S: Fractures of the shaft of the humerus. An epidemiological study of 401 fractures. J Bone Joint Surg Br 2006;88:1469-1473.

37 Masuyama R, Nakaya Y, Katsumata S, Kajita Y, Uehara M, Tanaka S, Sakai A, Kato S, Nakamura T, Suzuki K: Dietary calcium and phosphorus ratio regulates bone mineralization and turnover in vitamin $\mathrm{D}$ receptor knockout mice by affecting intestinal calcium and phosphorus absorption. J Bone Miner Res 2003;18:1217-1226.

38 Martin-Malo A, Rodriguez M, Martinez ME, Torres A, Felsenfeld AJ: The interaction of PTH and dietary phosphorus and calcium on serum calcitriol levels in the rat with experimental renal failure. Nephrol Dial Transplant 1996;11:1553-1558

39 Bover J, Jara A, Trinidad P, Rodriguez M, Felsenfeld AJ: Dynamics of skeletal resistance to parathyroid hormone in the rat: effect of renal failure and dietary phosphorus. Bone 1999;25:279-285. 